\title{
FOXTAIL MILLET (SETARIA ITALICA (L.) P. BEAUVOIS) QUALITY RESPONSE TO FERTILIZER LEVELS, HERBICIDE, AND SELENIUM
}

\author{
YANG, Y. J. ${ }^{1}-$ GUO, M. J ${ }^{1}-$ PANG, Y. F. ${ }^{1}-$ SHAO, Q. L. ${ }^{1}-$ WU, Y. Z. ${ }^{1}-$ ZHAO, H. M. ${ }^{1}-$ JI, A. Q. ${ }^{1}$ \\ - MA, J. H. ${ }^{1}-$ SONG, X. E. ${ }^{2}-$ SUN, C. Q. ${ }^{3}-$ YANG, X. F. $^{1}-$ FENG, Z. W. ${ }^{4 *}$ \\ ${ }^{1}$ College of Biological Sciences and Technology, Jinzhong University, Jinzhong 030600, China \\ (phone: +86-351-398-5785) \\ ${ }^{2}$ Key Laboratory of Crop Chemical Regulation and Chemical Weed Control, Agronomy \\ College, Shanxi Agricultural University, Taigu 030801, China \\ (phone: +86-354-628-9272)
}

${ }^{3}$ Institute of Crop Sciences, Shanxi Academy of Agricultural Sciences, Taiyuan 030031, China (phone: +86-351-712-3700)

${ }^{4}$ Technology Department, Shanxi Academy of Agricultural Sciences, Taiyuan 030031, China (phone: +86-351-707-3254)

*Corresponding author

e-mail:yyj1210@sina.com

(Received $19^{\text {th }}$ Apr 2021; accepted $30^{\text {th }}$ Aug 2021)

\begin{abstract}
Foxtail millet (Setaria italica (L.) P. Beauvois) is a high-nutrition food source. It is commonly consumed in Africa, Asia, Central America, and South America. The key to popularize high-quality foxtail millet in accordance with local conditions is quantifying the impacts of cultivation conditions on its quality. Here, we determined the effects of different fertilizer levels nitrogen $(\mathrm{N})$, tetraphosphorus decaoxide $\left(\mathrm{P}_{2} \mathrm{O}_{5}\right)$, and potassium oxide $\left(\mathrm{K}_{2} \mathrm{O}\right)$, tribenuron-methyl (TBM) herbicide, and selenium $(\mathrm{Se})$ on the quality of foxtail millet Jingu 54 using a quadratic general rotation combination design. The first principal component, which could explain $57.41 \%$ of the total variance of grain quality, was chosen as the comprehensive quality of Jingu 54 via principal component analysis. The effects of fertilizer levels and $\mathrm{Se}$ on comprehensive quality of Jingu 54 were significant $(\mathrm{P}<0.05)$, except for TBM. The effects of $\mathrm{N} \times$ $\mathrm{K}_{2} \mathrm{O}, \mathrm{N} \times \mathrm{TBM}$, and $\mathrm{K}_{2} \mathrm{O} \times$ TBM interactions reached significance for the comprehensive quality of Jingu $54(\mathrm{P}<0.05)$. The grain quality of Jingu 54 was predict by regression equation $\left(\mathrm{P}=0.0048, \mathrm{R}^{2}=0.8451\right)$. Recommended cultivation conditions are $108.31 \mathrm{~kg} \mathrm{ha}^{-1}, 94.80 \mathrm{~kg} \mathrm{ha}^{-1}, 105.03 \mathrm{~kg} \mathrm{ha}^{-1}, 88.08 \mathrm{~g} \mathrm{ha}^{-1}$, and $18.48 \mathrm{~g}_{\text {ai ha }}{ }^{-1}$ for $\mathrm{N}, \mathrm{P}_{2} \mathrm{O}_{5}, \mathrm{~K}_{2} \mathrm{O}$, Se, and TBM, respectively. The maximum predicted comprehensive quality of Jingu 54 was 56.85 . This study lays a theoretical foundation for achieving high quality Jingu 54 in the field.
\end{abstract}

Keywords: Jingu 54, comprehensive quality, principal component analysis, response surface methodology, tribenuron-methyl herbicide

\section{Introduction}

Foxtail millet (Setaria italica (L.) P. Beauvois) is known as the first of five cereals grain has high nutritional value (Sachdev et al., 2021). It is second only to wheat and maize in dry farming of north China and characterized by small genome, short growth cycle and tolerance to drought stress (Jones and Liu, 2009; Yang et al., 2012; Veeranagamallaiah et al., 2008). Some studies have investigated the effects of cultivation conditions on crop quality in wheat (Zörb et al., 2018; Xia et al., 2019), maize (Chilimba, et al., 2012; Guo et al., 2020), and rice (Chen and Chen, 2019; Huang, 
2020), but few have examined the cultivation conditions on quality of foxtail millet. Moreover, existing studies have focused on the relationship between individual quality indicators of foxtail millet and individual cultivation conditions by using statistical methods such as simple correlation analysis, which lacks comprehensiveness and is insufficient at explaining the complex interaction between different factors (Powers et al., 2020).

Principal component analysis (PCA) is a widely used statistical method for reducing variable dimensionality. Actually, as a multivariate correlation method, PCA disintegrates a few of inter-correlated variables into smaller sets of clusters which are composed of variables with lower or no degree of correlation (Anju and Banerjee, 2012). Similarly, as a statistical modeling and analysis technique, response surface methodology (RSM) is very popular in optimizing multiple variables (Mao et al., 2018; Montgomery, 2008). Hence, RSM has widespread application prospects in processing biotechnology, such as protein extraction, biofuel production, fermentation, and enzyme immobilization (Feng and Zhang, 2020; Abdel-Fattah et al., 2002; Liu et al., 2003; Adinarayana and Ellaiah, 2002). Moreover, RSM had been used on seedlings, and canola (Brassica napus L.) (Dong et al., 2011; Koocheki et al., 2014) culture, Chinese white poplar (Populus tomentosa Carr.). However, its application in optimization of foxtail millet cultivation conditions is barely explored.

Improper fertilization levels and fertilization methods will reduce the efficiency of fertilizers and also increase environmental pollution, thus hampering the quality of foxtail millet. The effects of nitrogen $(\mathrm{N})$, phosphorus $(\mathrm{P})$, potassium $(\mathrm{K})$, and their interaction on the quality of millet have rarely been reported. In addition, exogenous selenium (Se) can increase the content of lutein in tomato (Pezzarossa et al., 2013). It was reported that foliar application Se increased the concentration of iron and zinc in colored-grain wheat (Xia et al., 2019). Whether Se addition also benefits the quality of foxtail millet and affects yellow pigment content in foxtail millet grains is unknown. Finally, while the effect of herbicides on yield components has been reported (Guo et al., 2019; Suganthi et al., 2013; Robinson et al., 2013), its impact on the quality of foxtail millet is not well-understood.

The foxtail millet variety used in this study is Jingu 54, which was breeded from Jingu 21 (a dominant foxtail millet in China) and Jingu 20 (high yielding and drought tolerance). Jingu 54 show a specific characteristic in high yielding, quality and Se enrichment. However, the sown area of Jingu 54 in Shanxi province is about 0.5 million acres. The object of this study was to (1) obtain a comprehensive quality measurement of foxtail millet Jingu 54 by PCA, and (2) assess the effects of fertilizer levels, tribenuron-methyl (TBM) herbicide, and Se on quality of foxtail millet. We carried out field experiments based on 5-factor-5-level quadratic general rotary combination design. Based on the experimental results, the optimal cultivation conditions were determined, thus providing a guidance for future quality improvement of foxtail millet.

\section{Materials and methods}

\section{Experimental site and materials}

Field experiments were carried out in the Agricultural Experimental Station of Shanxi Agricultural University in Taigu County, Jinzhong City, Shanxi, China. An average annual rainfall of $462.9 \mathrm{~mm}$ and $9.9{ }^{\circ} \mathrm{C}$ of the annual average temperature are 
owned by the study site which has a temperate continental climate. The meteorological data of the experimental locations throughout the growth season of foxtail millet (MaySeptember) in 2019 are shown in Table 1.

Table 1. Meteorological data of the experimental sites during growing season of foxtail millet (May-September) in 2019

\begin{tabular}{|c|c|c|c|c|c|}
\hline \multirow{2}{*}{ Month } & \multirow{2}{*}{ Precipitation (mm) } & \multicolumn{2}{|c|}{ Temperature $\left({ }^{\circ} \mathrm{C}\right)$} & \multirow{2}{*}{$\begin{array}{c}\geq 20^{\circ} \mathrm{C} \text { accumulated } \\
\text { temperature }\left({ }^{\circ} \mathrm{C}\right)\end{array}$} & \multirow{2}{*}{$\begin{array}{l}\text { Sunshine } \\
\text { hours (h) }\end{array}$} \\
\hline & & Min & Max & & \\
\hline 5 & 30.1 & 2.6 & 35.1 & 329.1 & 277.0 \\
\hline 6 & 41.6 & 12.7 & 35.2 & 708.0 & 224.2 \\
\hline 7 & 63.8 & 12.1 & 37.0 & 768.8 & 229.9 \\
\hline 8 & 42.2 & 10.5 & 33.8 & 706.8 & 214.0 \\
\hline 9 & 73.9 & 7.4 & 34.2 & 218.4 & 217.0 \\
\hline
\end{tabular}

The test variety was the foxtail millet Jingu 54. Strawberries were cultivated for rotation with foxtail millet Jingu 54 in the experimental site. Soil texture was red sandy loam and with a medium organic matter content $\left(17.9 \mathrm{~g} \mathrm{~kg}^{-1}\right)$. Soil texture was characteristic of red sandy loam and a medium organic matter content $\left(17.9 \mathrm{~g} \mathrm{~kg}^{-1}\right)$. Soil $\mathrm{pH}$ was 8.2. Soil involves original soil-available $\mathrm{K}_{2} \mathrm{O}\left(93 \mathrm{mg} \mathrm{kg}^{-1}\right), \mathrm{N}\left(76 \mathrm{mg} \mathrm{kg}^{-1}\right)$, and $\mathrm{P}_{2} \mathrm{O}_{5}\left(29 \mathrm{mg} \mathrm{kg}^{-1}\right)$ (Soil Survey Staff, 2014).

\section{Experimental design}

Quadratic general rotation combination design with a 5-factor-5-level was implemented to optimize fertilizer levels $\left(\mathrm{N}, \mathrm{P}_{2} \mathrm{O}_{5}\right.$, and $\left.\mathrm{K}_{2} \mathrm{O}\right)$, herbicide, and Se. The five independent factors ( $x_{1}$ to $x_{5}$ ) were studied at five different levels (coded: $-2,-1,0$, +1 , and +2 , respectively) (Table 2 ), at the central point with six repetitions and two replications at the axial and factorial points, respectively (Table 3). The recommended applicable dose of the herbicide was form $13.5 \mathrm{~g} \mathrm{ha}^{-1}$ to $22.5 \mathrm{~g} \mathrm{ha}^{-1}$. A total of 32 treatment combinationswith three replications were run in a completely randomized block design and protection rows were set around the experimental site. Each plot was $3 \mathrm{~m} \times 6 \mathrm{~m}$ in size. The plant density and the apllied row distance were 330,000 plants per hectare and $23 \mathrm{~cm}$, respectively. The best combination in 2019 was chosen for the verification test in 2020, planting on May 18, with a plot size of $6 \mathrm{~m} \times 6 \mathrm{~m}=36 \mathrm{~m}^{2}$ and 6 plots.

Table 2. Levels and codes of five experimental factors

\begin{tabular}{c|c|c|c|c|c}
\hline Code & $\mathbf{N}\left(\mathbf{k g ~ h a}^{-\mathbf{1}}\right)$ & $\mathbf{P}_{\mathbf{2}} \mathbf{O}_{\mathbf{5}}\left(\mathbf{k g ~ h a}^{-\mathbf{1}}\right)$ & $\mathbf{K}_{\mathbf{2}} \mathbf{O}\left(\mathbf{k g ~ h a}^{-\mathbf{1}}\right)$ & $\mathbf{S e}\left(\mathbf{g ~ h a}^{\mathbf{- 1}}\right)$ & Tribenuron-methyl $\left(\mathbf{g ~ a i ~ h a ~}^{\mathbf{- 1}}\right)$ \\
\hline-2 & 0 & 0 & 0 & 0 & 0 \\
-1 & 69 & 36 & 37.5 & 60 & 20 \\
0 & 138 & 72 & 75 & 120 & 40 \\
1 & 207 & 108 & 112.5 & 180 & 60 \\
2 & 276 & 144 & 150 & 240 & 80 \\
$\Delta \mathrm{j}$ & 69 & 36 & 37.5 & 60 & 20 \\
\hline
\end{tabular}


Table 3. Program and experimental results of quadratic general rotation design for quality traits comprehensive quality of foxtail millet

\begin{tabular}{|c|c|c|c|c|c|c|c|c|c|c|c|c|c|c|}
\hline No & $x_{1}$ & $x_{2}$ & $x_{3}$ & $x_{4}$ & $x_{5}$ & $\begin{array}{l}\text { Protein } \\
(\%)\end{array}$ & $\begin{array}{l}\text { Fat } \\
(\%)\end{array}$ & $\begin{array}{c}\text { Yellow } \\
\text { pigment } \\
\left(\mathrm{mg} \mathrm{kg}^{-1}\right)\end{array}$ & $\begin{array}{c}\text { Folic } \\
\text { acid } \\
\left(\operatorname{ug~g}^{-1}\right)\end{array}$ & $\begin{array}{c}\mathrm{Se} \\
\left(\mathrm{ug} \mathrm{kg}^{-1}\right)\end{array}$ & Alkali & Gel & Amylose & PC1 \\
\hline 1 & 1 & 1 & 1 & 1 & 1 & 9.9 & 5.28 & 11.48 & 1.76 & 48.59 & 2.6 & 95.43 & 16.46 & 50.72 \\
\hline 2 & 1 & 1 & 1 & -1 & -1 & 10.96 & 5.6 & 12.25 & 1.79 & 48.59 & 3.31 & 99.7 & 17.76 & 54.15 \\
\hline 3 & 1 & 1 & -1 & 1 & -1 & 10.47 & 4.5 & 10 & 1.86 & 49.15 & 2.98 & 85 & 14 & 43.88 \\
\hline 4 & 1 & 1 & -1 & -1 & 1 & 10.15 & 5.28 & 11.56 & 1.83 & 50.07 & 2.76 & 95.43 & 16.6 & 50.58 \\
\hline 5 & 1 & -1 & 1 & 1 & -1 & 9.95 & 4.96 & 11.13 & 1.89 & 49.15 & 2.64 & 91.15 & 15.88 & 48.07 \\
\hline 6 & 1 & -1 & 1 & -1 & 1 & 10.55 & 5.49 & 12.2 & 1.85 & 48.04 & 3.04 & 98.16 & 17.67 & 53.29 \\
\hline 7 & 1 & -1 & -1 & 1 & 1 & 9 & 4.99 & 11.01 & 1.87 & 50.26 & 2 & 91.5 & 15.69 & 47.51 \\
\hline 8 & 1 & -1 & -1 & -1 & -1 & 10.72 & 4.83 & 10.6 & 1.8 & 48.96 & 3.15 & 89.44 & 14.99 & 46.93 \\
\hline 9 & -1 & 1 & 1 & 1 & -1 & 9.05 & 5.45 & 12.22 & 1.83 & 46 & 2.04 & 97.65 & 17.7 & 52.95 \\
\hline 10 & -1 & 1 & 1 & -1 & 1 & 9.41 & 5.28 & 11.39 & 1.72 & 48.78 & 2.27 & 95.43 & 16.32 & 50.40 \\
\hline 11 & -1 & 1 & -1 & 1 & 1 & 9.63 & 5.23 & 11.67 & 1.83 & 46.93 & 2.42 & 94.74 & 16.79 & 50.87 \\
\hline 12 & -1 & 1 & -1 & -1 & -1 & 10.66 & 5.46 & 11.89 & 1.77 & 48.22 & 3.11 & 97.82 & 17.15 & 52.76 \\
\hline 13 & -1 & -1 & 1 & 1 & 1 & 9.44 & 4.68 & 10.31 & 1.84 & 49.52 & 2.29 & 87.39 & 14.52 & 44.97 \\
\hline 14 & -1 & -1 & 1 & -1 & -1 & 9.08 & 5.5 & 12.02 & 1.75 & 46.93 & 2.05 & 98.33 & 17.37 & 52.86 \\
\hline 15 & -1 & -1 & -1 & 1 & -1 & 9.52 & 5.15 & 11.46 & 1.86 & 49.15 & 2.35 & 93.72 & 16.43 & 49.57 \\
\hline 16 & -1 & -1 & -1 & -1 & 1 & 10.01 & 5.21 & 11.44 & 1.76 & 46.56 & 2.67 & 94.4 & 16.4 & 50.65 \\
\hline 17 & -2 & 0 & 0 & 0 & 0 & 9.63 & 5.41 & 12.07 & 1.81 & 46 & 2.42 & 97.14 & 17.45 & 52.73 \\
\hline 18 & 2 & 0 & 0 & 0 & 0 & 10.5 & 4.91 & 10.83 & 1.87 & 51 & 3 & 90.47 & 15.38 & 47.18 \\
\hline 19 & 0 & -2 & 0 & 0 & 0 & 9.6 & 5.32 & 11.91 & 1.78 & 48.78 & 2.4 & 95.94 & 17.18 & 51.33 \\
\hline 20 & 0 & 2 & 0 & 0 & 0 & 10.8 & 5.59 & 11.99 & 1.7 & 48.41 & 3.2 & 99.53 & 17.31 & 53.74 \\
\hline 21 & 0 & 0 & -2 & 0 & 0 & 11.15 & 5.19 & 11.29 & 1.82 & 49.33 & 3.44 & 94.23 & 16.15 & 50.20 \\
\hline 22 & 0 & 0 & 2 & 0 & 0 & 9.11 & 5.47 & 12.14 & 1.84 & 47.11 & 2.07 & 97.99 & 17.56 & 52.79 \\
\hline 23 & 0 & 0 & 0 & -2 & 0 & 10.01 & 5.4 & 12.27 & 1.9 & 47.11 & 2.67 & 96.97 & 17.78 & 52.78 \\
\hline 24 & 0 & 0 & 0 & 2 & 0 & 10.39 & 5.05 & 11.52 & 1.89 & 49.89 & 2.93 & 92.35 & 16.54 & 49.14 \\
\hline 25 & 0 & 0 & 0 & 0 & -2 & 10.09 & 5.65 & 12.37 & 1.84 & 46 & 2.73 & 100.38 & 17.95 & 54.86 \\
\hline 26 & 0 & 0 & 0 & 0 & 2 & 9.68 & 5.17 & 11.38 & 1.83 & 49.33 & 2.45 & 93.89 & 16.29 & 49.59 \\
\hline 27 & 0 & 0 & 0 & 0 & 0 & 11.62 & 5.65 & 12.4 & 1.8 & 48.22 & 3.75 & 100.38 & 18.01 & 54.99 \\
\hline 28 & 0 & 0 & 0 & 0 & 0 & 11.81 & 5.62 & 12.6 & 1.83 & 49.52 & 3.87 & 99.87 & 18.34 & 54.77 \\
\hline 29 & 0 & 0 & 0 & 0 & 0 & 10.61 & 5.74 & 12.59 & 1.81 & 48.78 & 3.07 & 101.58 & 18.31 & 55.30 \\
\hline 30 & 0 & 0 & 0 & 0 & 0 & 11.37 & 5.72 & 12.73 & 1.86 & 48.78 & 3.58 & 101.24 & 18.56 & 55.59 \\
\hline 31 & 0 & 0 & 0 & 0 & 0 & 12 & 5.49 & 12.25 & 1.81 & 48.59 & 4 & 98.16 & 17.76 & 53.78 \\
\hline 32 & 0 & 0 & 0 & 0 & 0 & 11.18 & 6 & 13 & 1.79 & 47.48 & 3.45 & 105 & 19 & 57.99 \\
\hline
\end{tabular}

$x_{1}-\mathrm{N}, x_{2}-\mathrm{P}_{2} \mathrm{O}_{5}, x_{3}-\mathrm{K}_{2} \mathrm{O}, x_{4}-\mathrm{Se}, x_{5}$-tribenuron-methyl, $\mathrm{PC} 1$-the first principal component

Uniform seeds were sown on May 6, 2019 using a 2BX-3 small seeder (College of Engineering, Shanxi Agricultural University). Seedlings with at least three fully expanded leaves were thinned in accordance with plant spacing. One half of $\mathrm{N}$ was applied as a basal fertilizer, and the other half as a top-dressing at the jointing-booting stage. $\mathrm{K}_{2} \mathrm{O}$ and $\mathrm{P}_{2} \mathrm{O}_{5}$ were sereved as supplement natural fertilizers. Fertilizers included urea $(\mathrm{N} 46 \%)$, triple superphosphate $\left(\mathrm{P}_{2} \mathrm{O}_{5} 42 \%\right)$, and sulfate of potash $\left(\mathrm{K}_{2} \mathrm{O} 50 \%\right)$. Different dosages of TBM herbicide (10\%) and water as control were applied on foxtail millet Jingu 54 seedlings at five-leaf stage. Different dosages of selenite selenium $\left(\mathrm{Na}_{2} \mathrm{SeO}_{3}\right)$ were sprayed on the leaf surface during the filling stage. Plots were irrigated and prepared by rotary tillage before sowing. Weed control was undertaken by intertillage twice during the experimental period.

The response surface design, which (1) significantly reduces the number of experiments $(n=32)$ without loss of information when compared to the 5-factor-5-level 
full factorial design $\left(n=5^{5}\right)$; (2) simultaneously analyzes the effects of linear, quadratic, and interaction terms of target factors; and (3) obtains a prediction model with a curved surface, is the main advantage of the current study. Although the orthogonal design may decrease the number of trials as well, it only examines the isolated experimental sites one at a time. In contrast, the response surface design enables for ongoing analysis of the experimental levels throughout the optimization process. The latter approach may produce equal variances at experimental sites with equal distance to the center point, overcoming the limitation of orthogonal design methods and improving optimization accuracy. Using a response surface design, optimal conditions for comprehensive quality of foxtail millet can be found. The research took into account all interactions between fertilizer levels, Se, and herbicide, yielding more accurate findings than prior studies that just looked at single-factor impacts (Yang et al., 2018).

\section{Measurement}

The gel consistency was determined using a method described by Tran et al. (2011) with slight modifications. Finely grounded foxtail millet grain $(100 \mathrm{mg})$ in duplicate were putted into $13 \mathrm{~mm} \times 100 \mathrm{~mm}$ tubes which were respectively filled with $200 \mu \mathrm{L}$ ethyl alcohol (95\%), $0.025 \%$ thymol blue, $2.5 \mathrm{~mL} 0.15 \mathrm{~N} \mathrm{KOH}$. The tubes were mixed using a Vortex Genie mixer and then placed in a vigorously boiling water bath for $8 \mathrm{~min}$, held at room temperature for $5 \mathrm{~min}$, and cooled in an ice water bath for $20 \mathrm{~min}$. After this, tubes were laid horizontally on a light box on top of graphing paper. Measure the distance that the gel migrated in the tube after $1 \mathrm{~h}$.

The amylose content in foxtail millet starches was determined according to the procedure of the American Association of Cereal Chemists (2000).

The alkali digestion value was measured from twenty intact and fully mature foxtail millet grains of uniform size that were placed in a Petri dish. $10 \mathrm{~mL} 1.7 \%$ potassium hydroxide $(\mathrm{KOH})$ solution was added to each Petri dish until the grains were completely submerged. The grains remained dispersed to facilitate decomposition and covered with a lid. The samples were placed in a $30{ }^{\circ} \mathrm{C}$ thermostat incubator (BIC-300, Shanghai Boxun Industry \& Commerce Co., Ltd. Medical Equipment Factory) for $6 \mathrm{~h}$ and the decomposition of each grain was then observed. The degree of decomposition was recorded according to Table 4 . The alkali digestion value was calculated as follows: $A=\sum(G \times N) / 7$, where $A$ is alkali digestion value, $G$ is grade of each grain, and $N$ is number of grains at the same degree.

Table 4. Standard for alkali digestion value of foxtail millet grain samples

\begin{tabular}{c|c|c}
\hline Standard & Degree of decomposition & Definition \\
\hline 1 & Grain unchanged & White core in grain \\
2 & Grain expanded & White core in grain, with powdery ring \\
3 & Grain expanded, with incomplete or narrow ring & White core in grain, with flocculent or nebulous ring \\
4 & Grain enlarged, with complete and wide ring & Cotton white core in grain, with nebulous ring \\
5 & Grain cracked, with complete and wide ring & Cotton white core in grain, with clear ring \\
6 & Grain partially dispersed and dissolved, blended with ring & Cloud white core in grain, with no ring \\
7 & Grain completely dispersed & Both core and ring disappeared in grain \\
\hline
\end{tabular}

The crude protein and fat content of grain samples were determined by the methods described in Association of Official Analytical Chemists (AOAC, 2000). Percentage 
crude protein $(\mathrm{CP} \%)$ was determined by the Kjeldahl method and calculated based on the percentage $\mathrm{N}(\mathrm{N} \%)$ obtained: $\mathrm{CP} \%=\mathrm{N} \% \times 6.25$. Fat content $(\%)$ was detected by the Soxhlet extraction technique.

Total $500 \mathrm{mg}$ finely grounded foxtail millet grain (was acid-digested with $5 \mathrm{~mL} \mathrm{70 \%}$ superior-grade pure nitric acid and $2 \mathrm{~mL} \mathrm{30 \%} \mathrm{hydrogen} \mathrm{peroxide} \mathrm{to} \mathrm{measure} \mathrm{Se.} \mathrm{With}$ ultrapure water $\left(18.2 \mathrm{M} \Omega \mathrm{cm}^{-1}\right)$ the digested samples were diluted to $25 \mathrm{~mL}$. We analyzed the concentration of $\mathrm{Se}$ in the digestion solution by atomic fluorescence spectrometry (AFS-933, Beijing Jitian Instrument Co., Ltd.).

Folic acid was determined in exactly $2.5 \mathrm{~g}$ foxtail millet grain. Sample was weighed into $25 \mathrm{~mL} 0.1 \mathrm{~mol} \mathrm{~L}^{-1}$ potassium dihydrogen phosphate $\left(\mathrm{KH}_{2} \mathrm{PO}_{4}\right)$ and incubated in a $50{ }^{\circ} \mathrm{C}$ thermostat water bath for $8 \mathrm{~h}$. The sample was then centrifuged in a high-speed refrigerated centrifuge (Neofuge 15R, Shanghai Lishen Scientific Equipment Co., Ltd.) at $5000 \mathrm{rpm}$ for $10 \mathrm{~min}$. The supernatant was collected, followed by addition of $0.5 \mathrm{~g}$ aniline-treated activated $\mathrm{C}$. The mixture was thoroughly vortexed and then heated to boiling in a water bath (DK-S26, Shanghai Jinghong Experimental Equipment Co., Ltd.) for $10 \mathrm{~min}$. The sample was filtered and the supernatant was discarded. The residue was washed five times with $7 \mathrm{~mL} \mathrm{3 \%}$ ammonia: $70 \%$ ethanol. The eluate was evaporated and concentrated to $5 \mathrm{~mL}$, followed by addition of $1 \mathrm{~mL} 2 \%$ glacial acetic acid. Thereafter, $0.04 \%$ potassium permanganate $\left(\mathrm{KMnO}_{4}\right)$ was added dropwise until the color of the solution no longer changed. Furthermore, 3\% hydrogen peroxide $\left(\mathrm{H}_{2} \mathrm{O}_{2}\right)$ was added until the color of $\mathrm{KMnO}_{4}$ faded. The solution was diluted to a volume of $10 \mathrm{~mL}$. The fluorescence intensity was measured using a fluorescence spectrophotometer (BioSpectrometer fluorescence, Germany Eppendorf) at $\mathrm{Ex}=370 \mathrm{~nm}$ and $\mathrm{Em}=443 \mathrm{~nm}$ (Shao et al., 2014).

The content of grain yellow pigment was determined using the method described by Ning et al. (2016). The absorbance was measured at $450 \mathrm{~nm}$ using a spectrophotometer (UV-2400, Shanghai Sunny Hengping Scientific Instrument Co., Ltd.).

\section{Statistical analysis}

All treatments were performed at triplicate and results presented as mean values. We collected the crops $(2 \mathrm{~m} \times 2 \mathrm{~m})$ in the middle of each plot for lab analysis to minimize the marginal impact. Using SAS 9.4 software (SAS Institute Inc., Cary, NC, USA), all data analysis were processed. Comprehensive quality of foxtail millet was obtained by principal component analysis (PCA). Quadratic regression model was used for optimizing the cultivation conditions of foxtail millet for fertilizer levels, herbicide and Se. Effects of factorial interactions on grain quality were based on contour plots with Graphpad prism 8.0.

\section{Results}

\section{PCA of quality indicators of foxtail millet}

To analyze the relationship between the cultivation conditions and grain quality of foxtail millet, PCA was used. Only two eigenvalues were $>1$ and explained $82.34 \%$ of the total variance in grain quality (Table 5). As a result, the first two eigenvalues were picked out for further analysis; other small but non-zero eigenvalues were discarded to set up some potential contributing source factors. From the rotated component matrix (Table 6), it was noticeable that all quality parameters were clearly illustrated by the 
first two principal components. The first principal component (PC1) explained $57.41 \%$ of the variance including protein, fat, folic acid, gel consistency, amylase, alkali digestion value, yellow pigment, and Se. Obviously, the second principal component (PC2), accounting for $24.92 \%$ of the variance, had high loadings for protein, Se, and alkali digestion value. Consequently, PC1 was chosen to represent the comprehensive quality of foxtail millet.

Table 5. Eigenvalues, contribution, and cumulative contribution of the correlation matrix of indicators for comprehensive quality of foxtail millet

\begin{tabular}{c|c|c|c}
\hline Principal component & Eigenvalue & Contribution proportion (\%) & Cumulative (\%) \\
\hline F1 & 4.5926 & 57.4080 & 57.4080 \\
F2 & 1.9943 & 24.9285 & 82.3365 \\
F3 & 0.9334 & 11.6670 & 94.0035 \\
F4 & 0.4571 & 5.7140 & 99.7175 \\
F5 & 0.0225 & 0.2818 & 99.9993 \\
F6 & 0.0000 & 0.0004 & 99.9997 \\
F7 & 0.0000 & 0.0002 & 99.9999 \\
F8 & 0.0000 & 0.0001 & 100.0000 \\
\hline
\end{tabular}

Table 6. Eigenvectors of selected principal components for comprehensive quality of foxtail millet

\begin{tabular}{c|c|c}
\hline \multirow{2}{*}{ Quality indexes } & \multicolumn{2}{|c}{ Eigenvector } \\
\cline { 2 - 3 } & F1 & F2 \\
\hline protein & 0.2246 & 0.6032 \\
fat & 0.4583 & -0.0798 \\
Yellow pigment & 0.4522 & -0.0800 \\
Folic acid & -0.1509 & 0.1444 \\
Se & -0.2182 & 0.4753 \\
Alkali digestion value & 0.2243 & 0.6033 \\
Gel consistency & 0.4582 & -0.0803 \\
Amylose & 0.4522 & -0.0790 \\
\hline
\end{tabular}

\section{Effects of fertilizer levels, Se and hericide on grain comprehensive quality of foxtail millet}

Except for TBM, the effects of fertilizer levels and Se on comprehensive quality of foxtail millet were significant $(\mathrm{P}<0.05)$. The effect on comprehensive quality was the most significant for $\mathrm{Se}(P=0.0014)$, followed by $\mathrm{N}(P=0.0135), \mathrm{K}_{2} \mathrm{O}(P=0.0180)$, and $\mathrm{P}_{2} \mathrm{O}_{5}(P=0.0341)$ (Table 7$)$. In the design range, the effects of the five factors on comprehensive quality showed a parabolic trend, yet with various patterns (Fig. 1). With increasing $\mathrm{K}_{2} \mathrm{O}$, comprehensive quality first increased rapidly; when $\mathrm{K}_{2} \mathrm{O}$ exceeded 0.5, the quality showed a slow decline. With increasing $\mathrm{P}_{2} \mathrm{O}_{5}$ and $\mathrm{N}$, comprehensive quality climbed slightly and then gradually decreased. With increasing Se and TBM, comprehensive quality increased slightly and then plummeted. 
Table 7. Test of significance for the coefficients of regression equation for comprehensive quality of foxtail millet

\begin{tabular}{c|c|c|c|c|c|c}
\hline Term & Sum of square & DF & Mean square & Partial correlation & F-value & P-value \\
\hline$x_{1}$ & 18.3750 & 1 & 18.3750 & -0.6631 & 8.6328 & $0.0135^{*}$ \\
$x_{2}$ & 12.4416 & 1 & 12.4416 & 0.5891 & 5.8452 & $0.0341^{*}$ \\
$x_{3}$ & 16.4011 & 1 & 16.4011 & 0.6418 & 7.7054 & $0.0180^{*}$ \\
$x_{4}$ & 38.4054 & 1 & 38.4054 & -0.7882 & 18.0434 & $0.0014^{* *}$ \\
$x_{5}$ & 6.7416 & 1 & 6.7416 & -0.4728 & 3.1673 & 0.1027 \\
$x_{1} \times x_{1}$ & 60.8736 & 1 & 60.8736 & -0.8498 & 28.5992 & $0.0002^{* *}$ \\
$x_{2} \times x_{2}$ & 18.5659 & 1 & 18.5659 & -0.6650 & 8.7225 & $0.0131^{*}$ \\
$x_{3} \times x_{3}$ & 32.6839 & 1 & 32.6839 & -0.7633 & 15.3553 & $0.0024^{* *}$ \\
$x_{4} \times x_{4}$ & 41.4913 & 1 & 41.4913 & -0.7995 & 19.4932 & $0.0010^{* *}$ \\
$x_{5} \times x_{5}$ & 22.3593 & 1 & 22.3593 & -0.6989 & 10.5047 & $0.0079^{* *}$ \\
$x_{1} \times x_{2}$ & 1.8225 & 1 & 1.8225 & -0.2687 & 0.8562 & 0.3746 \\
$x_{1} \times x_{3}$ & 25.0000 & 1 & 25.0000 & 0.7186 & 11.7453 & $0.0057^{* *}$ \\
$x_{1} \times x_{4}$ & 2.6082 & 1 & 2.6082 & -0.3166 & 1.2254 & 0.2919 \\
$x_{1} \times x_{5}$ & 25.8064 & 1 & 25.8064 & 0.7241 & 12.1242 & $0.0051^{* *}$ \\
$x_{2} \times x_{3}$ & 1.9600 & 1 & 1.9600 & 0.2779 & 0.9208 & 0.3579 \\
$x_{2} \times x_{4}$ & 1.0712 & 1 & 1.0712 & 0.2092 & 0.5033 & 0.4928 \\
$x_{2} \times x_{5}$ & 0.0016 & 1 & 0.0016 & -0.0083 & 0.0008 & 0.9786 \\
$x_{3} \times x_{4}$ & 1.5006 & 1 & 1.5006 & -0.2454 & 0.7050 & 0.4190 \\
$x_{3} \times x_{5}$ & 14.2884 & 1 & 14.2884 & -0.6156 & 6.7129 & $0.0251^{*}$ \\
$x_{4} \times x_{5}$ & 0.1190 & 1 & 0.1190 & 0.0711 & 0.0599 & 0.8174 \\
\hline
\end{tabular}

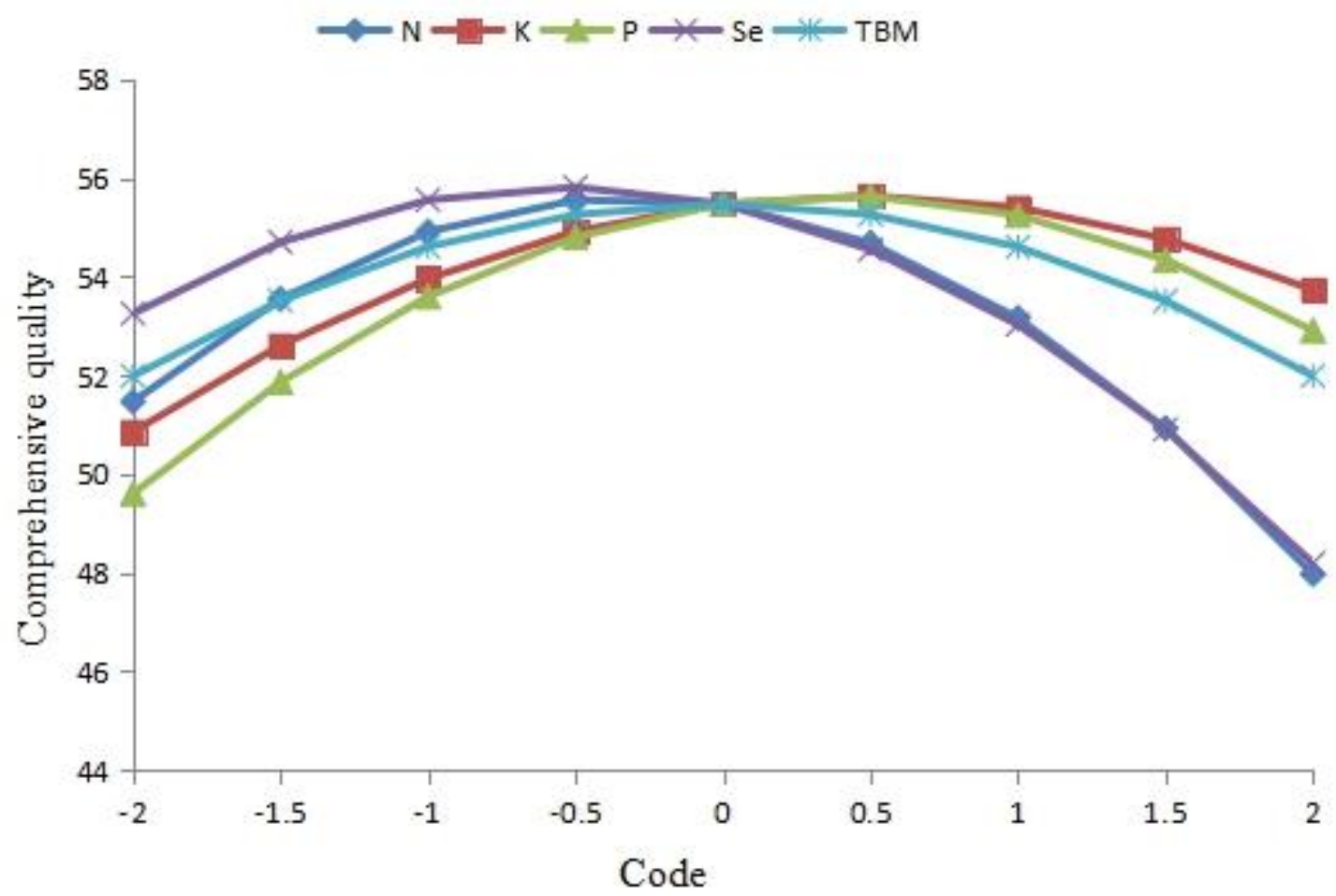

Figure 1. Effects of single factors on comprehensive quality of Jingu 54 
The effects of $\mathrm{N} \times \mathrm{K}_{2} \mathrm{O}, \mathrm{N} \times \mathrm{TBM}, \mathrm{K}_{2} \mathrm{O} \times \mathrm{TBM}$ interactions reached statistical significance for comprehensive quality of foxtail millet (Table 7). The contour plots (Fig. 2) were mapped to show the interactive effects of $\mathrm{N} \times \mathrm{K}_{2} \mathrm{O}, \mathrm{N} \times \mathrm{TBM}, \mathrm{K}_{2} \mathrm{O}$ $\times$ TBM.
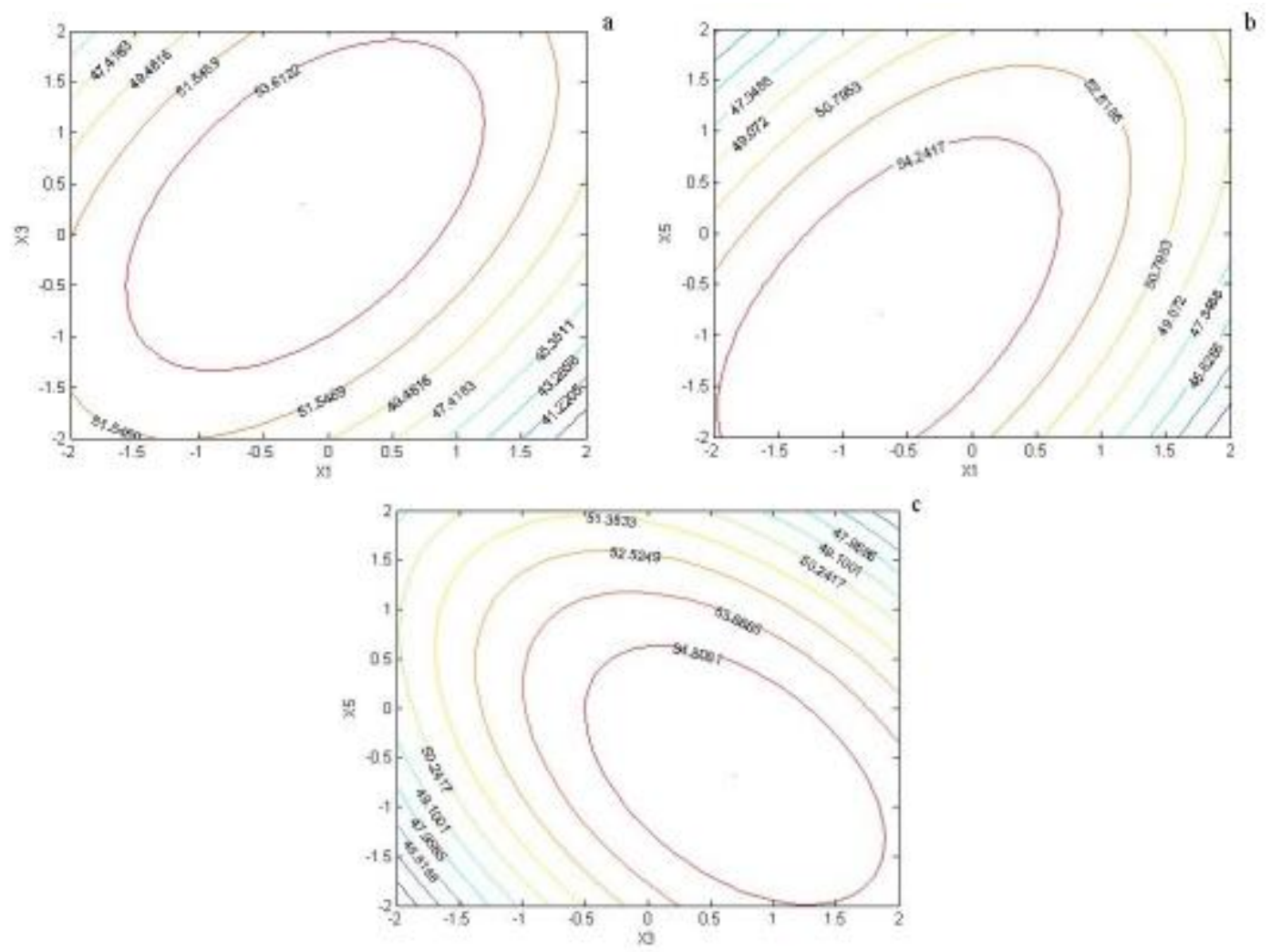

Figure 2. Significant effects of factor interactions on comprehensive quality of Jingu 54. $a$ : $N \times$ $\mathrm{K}_{2} \mathrm{O} ; b: \mathrm{N} \times \mathrm{TBM} ; \mathrm{c}: \mathrm{K}_{2} \mathrm{O} \times \mathrm{TBM}$

When $\mathrm{P}_{2} \mathrm{O}_{5}$, TBM and Se were fixed at the zero level, the comprehensive quality of foxtail millet decreased and then increased with the increase of $\mathrm{N}$ and $\mathrm{K}_{2} \mathrm{O}$ (Fig. 2a). The effect of $\mathrm{N}$ was greater at higher $\mathrm{K}_{2} \mathrm{O}$ levels than at lower $\mathrm{K}_{2} \mathrm{O}$ levels. At lower $\mathrm{N}$ levels, enriching $\mathrm{K}_{2} \mathrm{O}$ caused little change in the comprehensive quality; at higher $\mathrm{N}$ levels, comprehensive quality first increased rapidly and then decreased slowly with the increase of $\mathrm{K}_{2} \mathrm{O}$.

When $\mathrm{P}_{2} \mathrm{O}_{5}, \mathrm{~K}_{2} \mathrm{O}$, and $\mathrm{Se}$ were fixed at the zero level, increasing $\mathrm{N}$ caused a dramatic comprehensive quality increase at high TBM levels, but not at low TBM levels. With continued increase in $\mathrm{N}$ application, there was a downward trend in comprehensive quality (Fig. 2b). When TBM levels was increased at lower N levels, the comprehensive quality first increased slowly and then decreased rapidly. An opposite trend was observed in the comprehensive quality with increasing TBM levels at higher $\mathrm{N}$ levels.

When $\mathrm{N}, \mathrm{P}_{2} \mathrm{O}_{5}$, and Se were fixed at the zero level, comprehensive quality began to increase quickly and then dropped as TBM levels were increased at an appropriate (or lower) level of $\mathrm{K}_{2} \mathrm{O}$. When TBM levels were reduced at higher $\mathrm{K}_{2} \mathrm{O}$ levels, comprehensive quality was rapidly increased after a slow reduced (Fig. 2c). 


\section{Response of comprehensive quality of foxtail millet to fertilizer, herbicide and Se}

To obtain a practicable and effective model, the actual responses should be suitable for existing linear, two factor interactions, cubic, or quadratic model. The quadratic model was selected and validated in the analysis of variance. The results included Fisher variation ratio ( $F$ value), probability value ( $P$ value), lack of fit, and adjusted $R$ squared $\left(R_{A d j}{ }^{2}\right)$. The second-order polynomial equation for grain quality follows:

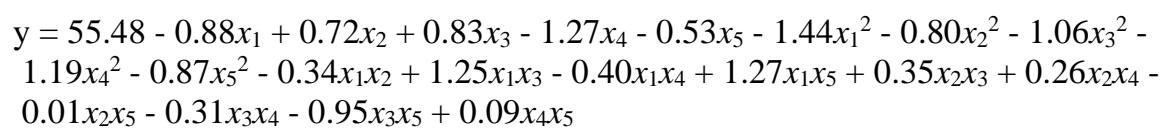

where $y$ is the predicted response of grain quality and $x_{1}, x_{2}, x_{3}, x_{4}$, and $x_{5}$ are coded values of $\mathrm{N}$ level, $\mathrm{P}_{2} \mathrm{O}_{5}$ level, $\mathrm{K}_{2} \mathrm{O}$ level, Se level, and TBM level, respectively.

The statistical significance of Equation 1 was evaluated by an $F$-test. The F-test of the response surface variances showed that the equation $\left(R^{2}\right.$ adj was 0.8451$)$ was statistically valid $(P<0.05)$, and lack of fit item test was not significant $(P>0.05)$. The optimal values of the selected factors in their respective coded values were: $x_{1}=$ $0.4303, x_{2}=0.6334, x_{3}=0.8007, x_{4}=-0.5320$, and $x_{5}=-1.0761$. Accordingly, the actual $\mathrm{N}$ level, $\mathrm{P}_{2} \mathrm{O}_{5}$ level, $\mathrm{K}_{2} \mathrm{O}$ level, Se level, and TBM level were $108.31 \mathrm{~kg} \mathrm{ha}^{-1}$, $94.80 \mathrm{~kg} \mathrm{ha}^{-1}, 105.03 \mathrm{~kg} \mathrm{ha}^{-1}, 88.08 \mathrm{~g} \mathrm{ha}^{-1}$, and $18.48 \mathrm{~g}^{2}$ ai ha ${ }^{-1}$, respectively. The maximum predicted comprehensive quality of foxtail millet was 56.85. Multivariate quadratic regression indicated that the relationship between the five factors and comprehensive quality of Jingu 54 was significant, which can be used for forecast of production.

\section{Verification of Jingu 54 cultivation conditions}

The theoretically optimum combination was not included in the 32 experimental treatment combinations developed in 2019. Six plots with an area of $6 \mathrm{~m} \times 6 \mathrm{~m}$ were chosen in May 2020 to further validate the optimum conditions of $108.31 \mathrm{~kg} \mathrm{ha}^{-1}$, $94.80 \mathrm{~kg} \mathrm{ha}^{-1}, 105.03 \mathrm{~kg} \mathrm{ha}^{-1}, 88.08 \mathrm{~g} \mathrm{ha}^{-1}$, and $18.48 \mathrm{~g} \mathrm{ha}^{-1}$ for $\mathrm{N}, \mathrm{P}_{2} \mathrm{O}_{5}, \mathrm{~K}_{2} \mathrm{O}$, selenium, and tribenuron-methyl, respectively. The comprehensive quality of Jingu 54 was 57.46, and the error with the projected value was 1.07 percent, which was extremely near to the model value, confirming the model's practicability.

\section{Discussion}

Cultivation conditions have a significant impact on the grain quality of foxtail millet. Existing research on the connection between cultivation circumstances and foxtail millet quality has often relied on simple correlation analysis, which cannot show the intricate interaction of internal regulation (Powers et al., 2020). Multiple statistical analyses were used in this study to gradually show that fertilizer levels, herbicide, and Se influence the grain quality of foxtail millet.

Both the quality indicators of foxtail millet and the growing circumstances were multidimensional factors in the research. As a result, determining optimum cultivation conditions influencing grain quality of foxtail millet proved challenging. PCA was initially utilized in the research to get the main component reflecting the comprehensive quality of foxtail millet. Furthermore, the most important cultivation factors influencing foxtail millet quality were identified, and an optimum connection model was developed 
using regression analysis. The optimum growing conditions were established, and the impacts of one-factor and two-factor interaction on comprehensive quality of foxtail millet were investigated. The above-mentioned progressive system analysis is also a quantitative comparison study of the development trend in a dynamic process. This technique overcomes the drawbacks of utilizing single indicators and methodologies, having limited and dispersed cultivation circumstances, and a lack of thorough research and assessment of the crop-cultivation connection. As a result, the results reached here are more trustworthy and may better represent the real circumstances, which meet the requirements of this research. Furthermore, the findings provide a logical decisionmaking foundation for future research and analysis of foxtail millet.

Foxtail millet grain quality is a multifaceted characteristic that includes nutritional quality, as well as cooking and eating quality (Suman et al., 2015). Based on the PCA findings, we chose PC1 to represent the comprehensive quality of foxtail millet since it contributed 57.41 percent of the total variance. This component comprised nutritional quality (protein, fat, yellow pigment, folic acid, and Se) as well as cooking and eating quality (gel consistency, amylase, alkali digestion value), and therefore accurately reflected the foxtail millet quality.

Reasonable fertilization settings may enhance crop quality while reducing nutrient loss and avoiding possible environmental issues (Wang et al., 2011). Our findings revealed that single factors $\mathrm{N}, \mathrm{P}$, and $\mathrm{K}$ had a substantial impact on the comprehensive quality of Jingu 54, and that the quality rose initially and then declined as fertilization increased ( $\mathrm{Li}, 2008)$. This may be because enhanced soil fertility raised the pace of grain filling, delayed the appearance of the filling phase, extended the filling time, and accelerated the accumulation of nitrogen, phosphorus, and assimilates in grains, all of which are beneficial to grain quality formation ( $\mathrm{Li}, 2008)$. Nitrogen and potassium may boost photosynthetic capacity, enhance pigments that absorb light energy, improve carbohydrate synthesis and transformation, and boost grain nutritional quality. However, overuse of a particular nitrogen fertilizer resulted in a decrease in quality (Wang et al., 2011). Tang et al. (2019) obtained similar results while researching the potential function of nitrogen fertilizer in rice quality regulation. Guo et al. (2020) demonstrated that judicious nitrogen fertilizer application may enhance the concentration of certain nutritional components in maize kernel and improve its quality. Zörb et al. (2018) demonstrated that nitrogen fertilizer aided protein accumulation in wheat. Chen and Chen (2019) discovered that phosphate fertilizer may enhance the amount of starch, crude protein, and amino acids in rice, as well as boost phosphorus absorption in rice and straw. Results indicated that the impact of N, P, and $\mathrm{K}$ on foxtail millet quality was at the following sequence $\mathrm{N}>\mathrm{P}>\mathrm{K}$, which was inconsistent with previous finding on beta-carotene and lutein of foxtail millet (Dong et al., 2018). The explanation for the discrepancy may be because the research was more thorough in its assessment of the plant's overall quality, including lutein.

Appropriate nitrogen, phosphorus, and potassium ratios may significantly enhance crop growth and development, accelerate the accumulation and transit of photosynthetic products after anthesis, and improve grain nutritional quality (Wang et al., 2010). According to the findings, the combination between $\mathrm{N}$ and $\mathrm{K}$ had a substantial impact on the quality of Jingu 54. When the potassium level is low, an excessively high nitrogen level will result in a decrease in quality, while when the potassium level is high, the higher the nitrogen level is within a specific range, the better the quality. The findings indicated that crop quality could not be improved in the presence of low 
nitrogen, but that quality deteriorated significantly as potassium treatment increased, suggesting that excessive potassium application should be avoided in the presence of low nitrogen. Because $\mathrm{N}$ and $\mathrm{K}$ complement each other in the process of plant metabolism, maintaining the proper $\mathrm{N} / \mathrm{K}$ ratio is essential to guarantee excellent quality (Wang et al., 2011). But the effects of the interaction of phosphorus, nitrogen, and potassium did not reach statistical significance for comprehensive quality of Jingu 54. There are many studies on the use of $\mathrm{N}, \mathrm{P}$, and $\mathrm{K}$ fertilizers in combination, although most of them focus on the impact of fertilization on crop yield or fertilizer efficiency. According to Wang et al. (2010) the interaction of $\mathrm{N}$ and $\mathrm{P}$ had a substantial impact on rice production, while the interaction of $\mathrm{N}$ and $\mathrm{K}$ was not significant. Wang et al. (2011) demonstrated that when the $\mathrm{K}$ level was low, a high $\mathrm{N}$ level resulted in a lower yield, while a higher $\mathrm{N}$ level in a specific range resulted in a greater yield, which was comparable to the findings of our research. However, research on the effect of $\mathrm{N}, \mathrm{P}$, and $\mathrm{K}$ interactions on crop quality is limited, making it difficult to determine a reasonable fertilization ratio for crop quality. This research provides a certain reference for the investigation of the effects of combined application of nitrogen, phosphorus, and potassium on crop quality.

This study revealed a significant role of Se in the comprehensive quality of Jingu 54. In consistent with our finding, previous studies have shown that exogenous Se can increase the content of lutein in tomato (Pezzarossa et al., 2013). Similarly, Se (at 0$810 \mathrm{~kg} \mathrm{ha}^{-1}$ ) increased the content of lutein in carrots by $94.2 \%$ (Biacs et al., 1995). However, other trials have shown that exogenous Se has no effect on the content of lutein in cabbage (Lefsrud et al., 2006) or tomato (Pezzarossa et al., 2014). The reason for the inconsistency of these results may be due to the concentrations of exogenous Se and/or the characteristics of the target crop. So far, there are few reports on the effect of Se on foxtail millet, especially regarding to their yellow pigment content. Previous investigation on corn shows that Se application on leaf surface does not influence mineral content in corn kernels (Wang et al., 2013). Studies on various crops such as corn (Chilimba et al., 2012), wheat (Broadley et al., 2010), and rice (Boldrinet et al., 2013) showed that the Se content in the grain has a linear relationship to the concentration of exogenous Se. This research also found that when selenium content rose, the quality of Jingu 54 improved at first, then declined. To avoid the negative health consequences of deficiency or excessive selenium intake appropriate dose should be chosen when applying selenium fertilizer to crops, so that selenium may completely exercise its biological activities of anti-oxidation and immune promotion (Boldrinet et al., 2013). The combination of selenium with nitrogen, phosphorus, potassium, and herbicide did not achieve a significant level of influence on the comprehensive quality. But most of them adopted orthogonal design without analyzing the interaction between factors (Long et al., 2019).

Weed competition has become an important limiting factor for crop growth and development, with chemical herbicides controlling weeds in the field while also reducing crop yields and quality (Iqbal et al., 2019; Javaid and Tanveer, 2013). Because yield and quality are two determinants of millet value (Chauhan and Openga, 2012), it is critical to investigate the effects of herbicides. The findings indicated that the quality of Jingu 54 rose initially and subsequently deteriorated as TBM herbicide concentration increased. Malalgoda et al. (2020) discovered that incorrect administration of fensulfuron-methyl may have a serious impact on agricultural seed protein content. The impact of herbicide stress on agricultural seed mineral content was suggested by Gugala 
et al. (2010, 2012) and Ning et al. (2015). The interaction between TBM and N (and K) had a substantial effect on the comprehensive quality of Jingu 54 in this research. The quality of Jingu 54 improved quickly initially and then declined slowly as TBM concentration increased at high nitrogen levels, indicating that nitrogen may mitigate pesticide damage at specific concentrations. When TBM was raised to a specific level at high potassium levels, the quality of Jingu 54 dropped quickly, which may be attributable to the suppression of potassium on TBM degradation (Huang, 2020). The effect of herbicides on crop quality can only be fully appreciated via a comprehensive investigation of soil and crop nutritional status, which necessitates further research.

\section{Conclusion}

It is the first time to report the effects of different fertilizer levels $\left(\mathrm{N}, \mathrm{P}_{2} \mathrm{O}_{5}\right.$, and $\mathrm{K}_{2} \mathrm{O}$ ), TBM herbicide, and Se on comprehensive quality of foxtail millet Jingu 54. The optimal application of $\mathrm{N}, \mathrm{P}, \mathrm{K}, \mathrm{Se}$ and herbicides could reduce waste, reduce pollution, and protect the ecological environment without affecting the quality of foxtail millet. Additionally, foxtail millet grain was reported to be enriched with Se through exogenous Se under the foliar application of Se. Our study established a multivariate quadratic regression model of comprehensive quality, which showed statistical significance and thus could be used for production prediction. Based on the regression model, optimal cultivation conditions were obtained for Jingu 54 under the following experimental conditions: $\mathrm{N}$ level, $\mathrm{P}_{2} \mathrm{O}_{5}$ level, $\mathrm{K}_{2} \mathrm{O}$ level, Se level, and TBM level as $108.31 \mathrm{~kg} \mathrm{ha}^{-1}, 94.80 \mathrm{~kg} \mathrm{ha}^{-1}, 105.03 \mathrm{~kg} \mathrm{ha}^{-1}, 88.08 \mathrm{~g} \mathrm{ha}^{-1}$, and $18.48 \mathrm{~g}$ ai ha ${ }^{-1}$, respectively. The maximum predicted comprehensive quality of foxtail millet was 56.85. Our study provides a valuable practice for the optimized cultivation management and targeted planting of high-quality foxtail millet. Because of the impact of soil environment and fertilization, the development of grain quality is a complicated process that has to be researched more thoroughly.

Acknowledgments. The study was supported by the Key Research and Development General Project in Shanxi Province, China (201703D221009-1), the Key Research and Development General Project in Shanxi Province, China (201903D221075), the Key Research and Development General Project in Shanxi Province, China (201903D221030), the Shanxi Science and Technology Development Project of Universities (2019L0884), maker team of Jinzhong University (jzxycktd2019027) and Innovation team of Jinzhong University (jzxyjscxtd202108).

\section{REFERENCES}

[1] Abdel-Fattah, Y. R., Abdel-Fattah, W. R., Zamilpa, R., Pierce, J. R. (2002): Numerical modelling of ferrous-ion oxidation rate in Acidithiobacillus ferroxidans ATCC 23270: optimization of culture conditions through statistically designed experiments. - Acta Microbiologica Polonica 51: 225-235.

[2] Adinarayana, K., Ellaiah, P. (2002): Response surface optimization of the critical medium components for the production of alkaline protease by a newly isolated. - Journal of Pharmaceutical Sciences 5: 272-278.

[3] American Association of Cereal Chemists (2000): AACC International Approved Methods. 9th Ed. - American Association of Cereal Chemists (AACC) International, St. Paul, Minnesota. 
[4] Anju, M., Banerjee, D. K. (2012): Multivariate statistical analysis of heavy metals in soils of a Pb-Zn mining area, India. - Environmental Monitoring and Assessment 184: 41914206.

[5] AOAC (2000): Official Methods of Analysis. 17th Ed. - Association of Official Analytical Chemists (AOAC), Gaithersburg, Maryland.

[6] Biacs, P. A., Daood, H. G., Kadar, I. (1995): Effect of Mo, Se, Zn, and Cr treatments on the yield, element concentration, and carotenoid content of carrot. - Journal of Agricultural and Food Chemistry 43: 589-591.

[7] Boldrin, P. F., Faquin, V., Ramos, S. J., Boldrin, K. V. F., Avila, F. W., Guilherme, L. R. G. (2013): Soil and foliar application of Se in rice biofortification. - Journal of Food Composition and Analysis 31: 238-244.

[8] Broadley, M. R., Alcock, J., Alford, J. (2010): Se biofortification of high-yielding winter wheat by liquid or granular Se fertilisation. - Plant and Soil 332: 5-18.

[9] Chauhan, B. S., Opeňa, J. L. (2012): Effect of tillage systems and herbicides on weed emergence, weed growth, and grain yield in dry-seeded rice systems. - Field Crops Research 137: 56-69.

[10] Chen, S. P., Chen, J. D. (2019): Effects of different phosphorus application rates on yield, quality and phosphate fertilizer utilization efficiency of rice submission date. - Anhui Agricultural Sciences Bulletin 25(13): 57-58, 109 (in Chinese).

[11] Chilimba, A. D. C., Young, S. D., Black, C. R. (2012): Agronomic biofortification of maize with Se (Se) in Malawi. - Field Crops Research 125: 118-128.

[12] Dong, W., Qin, J., Li, J. Y., Zhao, Y., Nie, L. S. (2011): Interactions between soil water content and fertilizer on growth characteristics and biomass yield of Chinese white poplar (Populus Tomentosa Carr.) seedlings. - Soil Science and Plant Nutrition 57(2): 303-312.

[13] Dong, Q. N., Liu, Y. F., Cheng, L. P., Guo, E., Shan, Y. G., Zhang, M. P. (2018): Effect of different fertilization conditions on the content of $\beta$-carotene and latein in foxtail millet. - Journal of Nuclear Agricultural Science. 32(5): 1003-1008 (in Chinese).

[14] Feng, Y. N., Zhang, X. F. (2020): Polysaccharide extracted from Huperzia serrata using response surface methodology and its biological activity. - International Journal of Biological Macromolecules 157: 267-275.

[15] Gugala, M., Zarzecka, K. (2010): The effect of weed control methods on magnesium and calcium content in edible pea seeds (Pisum sativum L.). - Journal of Elementology 15: 269-280.

[16] Gugala, M., Zarzecka, K., Mystkowska, I. (2012): Potato tuber content of magnesium and calcium depending on weed control methods. - Journal of Elementology 17: 247-254.

[17] Guo, M. J., Song, X. E., Shen, J., Wang, J. M., Zhao, X. T., Liu, S. G., Dong, S. Q., Yuan, X. Y., Wen, Y. Y., Guo, P. Y., Shi, X. X., Shi, Y. F. (2019): Precision orientation herbicide spraying against weeds in plastic-mulched fields of spring hybrid millet. Emirates Journal of Food and Agriculture 31(11): 837-846.

[18] Guo, S., Chen, Y. H., Chen, X. C., Chen, Y. L., Tang, Y., Yang, L., Wang, L., Qin, Y. S., Li, M. S., Chen, F. J., Lui, G. h., Gu, R. L., Yuan, L. X. (2020): Grain mineral accumulation changes in Chinese maize cultivars released in different decades and the responses to nitrogen fertilizer. - Front Plant Science 10: 1662.

[19] Huang, X. H. (2020): Exploring the Agronomic Effect of Nitrogen and Phosphorus Fertilizers and Herbicides Quinclorac in the Double-Season Rice Region of Jiangxi Province. - Zhejiang University, Hangzhou (in Chinese).

[20] Iqbal, M. F., Shad, G. M., Feng, Y. L., Liu, M. C., Wag, S., Lu, X. R., Iqbal, Z., Tarig. M. (2019): Efficacy of postemergence herbicides for controlling curled Dock (RUMEX CRISPUS L.) in wheat crops. - Applied Ecology and Environmental Research 17(6): 12753-12766.

[21] Javaid, M. M., and Tanveer, A. (2013): Optimization of application efficacy for post herbicides with adjuvants on three-cornered jack (Emex australis Steinheil) in wheat. Weed Technology 27: 437-444. 
[22] Jones, M. K., Liu, X. (2009): Origins of agriculture in East Asia. - Science 324: 730-731.

[23] Koocheki, A., Mahallati, M. N., Moradi, R., Mansoori, H. (2014): Optimizing water, N and crop density in canola cultivation using response surface methodology and central composite design. - Soil Science and Plant Nutrition 60(2): 286-298.

[24] Lefsrud, M. G., Kopsell, D. A., Kopsell, D. E. (2006): Kale carotenoids are unaffected by, whereas biomass production, elemental concentrations, and Se accumulation respond to, changes in Se fertility. - Journal of Agricultural and Food Chemistry 54: 1764-1771.

[25] Li, J. Q. (2008): Study on the influencing mechanisms of nitrogen and phosphorus nutrients on maize yield and quality in rainfed lands of the loess plateau. - Plant Nutrition and Fertilizer Science 14(6): 1042-1047 (in Chinese).

[26] Liu, C., Liu, Y., Liao, W., Wen, Z., Chen, S. (2003): Application of statistically-based experimental designs for the optimization of nisin production from whey. Biotechnology Letters 25: 877-882.

[27] Long, S. F., Wang, M., Wu, D. M., Liu, B., Huang, F. X., Xing, D. Y., Zhu, J. Q. (2019): Effect of combined application of selenium nitrogen phosphorus and potassium fertilizers on yield, appearance quality and selenium uptake of Paddy rice. - Journal of Yangtze University (Natural Science Edition) 16(1): 66-71, 124 (in Chinese).

[28] Malalgoda, M., Ohm, J. B., Howatt, K. A., Green, A., Simsek, S. (2020): Effects of preharvest glyphosate use on protein composition and shikimic acid accumulation in spring wheat. - Food Chemistry 332: 127422.

[29] Mao, K. J., Huang, P., Zhang, L., Yu, H. S., Zhou, X. Z., Ye, X. Y. (2018): Optimisation of extraction conditions for total saponins from Cynanchum wallichii using response surface methodology and its anti-tumour effects. - Natural Product Research 32(18): 2233-2237.

[30] Montgomery, D. C. (2008): Design and Analysis of Experiments. 7th Ed. - John Wiley \& Sons, New York.

[31] Ning, N., Yuan, X. Y., dong, S. Q., Wen, Y. Y., Guo, Z. P., Guo, M. J., Guo, P. Y. (2015): Grain yield and quality of foxtail millet (Setaria italica L.) in response to tribenuron-methyl. - Plos One 10(11): e0142557.

[32] Ning, N., Yuan, X. Y., Dong, S. Q., Wen, Y. Y., Gao, Z. P., Guo, M. J. (2016): Increasing Se and yellow pigment concentrations in foxtail millet (Setaria italica L.) grain with foliar application of Selenite. - Biological Trace Element Research 170: 245252.

[33] Pezzarossa, B., Rosellinia, I., Malorgio, F. (2013): Effect of Se enrichment of tomato plants on ripe fruit metabolism and composition. - Acta Horticultural 1012: 247-251.

[34] Pezzarossa, B., Rosellinia, I., Borghesib, E. (2014): Effects of Se-enrichment on yield, fruit composition and ripening of tomato (Solarium lycopersicum) plants grown in hydroponics. - Scientia Horticulturae 165: 106-110.

[35] Powers, D. N., Trunfio, N., Velugula-Yellela, S. R., Angart, P., Faustino, A., Agarabi, C. (2020): Multivariate data analysis of growth medium trends affecting antibody glycosylation. - Biotechnology Progress 36(1): e2903.

[36] Robinson, A. P., Simpson, D. M., Johnson, W. G. (2013): Response of glyphosatetolerant soybean yield components to dicamba exposure. - Weed Science 61: 526-536.

[37] Sachdev, N., Goomer, S., Singh, L. R. (2021): Foxtail millet: a potential crop to meet future demand scenario for alternative sustainable protein. - Journal of the Science of Food and Agriculture 101(3): 831-842.

[38] Shao, L. H., Wang, L., Bai, W. W., Liu, Y. J. (2014): Evaluation and analysis of folic acid content in millet from different ecological regions in Shanxi province. - Journal of Integrative Agriculture 47: 1265-1272.

[39] Soil Survey Staff (2014): Keys to Soil Taxonomy. 12th Ed. - USDA-NRCS, Washington, DC. 
[40] Suganthi, M., Muthukrishnan, P., Chinnusamy, C. (2013): Influence of early post emergence sulfonylurea herbicides on growth, yield parameters, yield and weed control efficiency in sugarcane. - Agronomy Journal 12: 59-63.

[41] Suman, V., Sarita, S., Neha, T. (2015): Comparative study on nutritional and sensory quality of barnyard and foxtail millet food products with traditional rice products. - Food Science and Technology Research 52: 5147-5155.

[42] Tang, S., Zhang, H. X., Liu, W. Z., Dou, Z., Zhou, Q. Y., Chen, W. Z., Wang. S. H., Ding, Y. F. (2019): Nitrogen fertilizer at heading stage effectively compensates for the deterioration of rice quality by effecting the search-related properties under elevated temperatures. - Food Chemistry 277: 455-462.

[43] Tran, N. A., Daygon, V. D., Resurreccion, A. P., Cuevas, R. P., Corpuz, H. M., Fitzgerald, M. A. (2011): A single nucleotide polymorphism in the Waxy gene explains a significant component of gel consistency. - Theoretical and Applied Genetics 123: 519525 .

[44] Veeranagamallaiah, G., Jyothsnakumari, G., Thippeswamy, M., Chandra Obul Reddy, P., Surabhi, G. K., Sriranganayakulu, G. (2008): Proteomic analysis of salt stress responses in foxtail millet (Setaria italica L. cv. Prasad) seedlings. - Plant Science 175: 631-641.

[45] Wang, C. A., Zhang, W. X., Zhao, L., Zhao, X. Z., Hou, W. P., Gao, L. W., Wang, B. L. (2010): Effect of amount of nitrogen, phosphorus and potassium fertilizer application on yield and quality of rice. - Journal of Jilin Agricultural Sciences 35(1): 28-33 (in Chinese).

[46] Wang, W. N., Lu, J. W., He, Y. Q., Li, X. H., Li, H. (2011): Effect of N, P, K fertilizer application on grain yield quality nutrient uptake and utilization of rice. - Chinese Journal of Rice Science 25(6): 645-653 (in Chinese).

[47] Wang, J. W., Wang, Z. H., Mao, H. (2013): Increasing Se concentration in maize grain with soil or foliar-applied selenite on the Loess Plateau in China. - Field Crops Research 150: 83-90.

[48] Xia, Q., Yang, Z. P., Xue, N. W., Dai, X. J., Zhang, X., Gao, Z. Q. (2019): Effect of foliar application of selenium on nutrient concentration and yield of colored-grain wheat in China. - Applied Ecology and Environmental Research 17(2): 2187-2202.

[49] Yang, X. Y., Wan, Z. W., Perry, L., Lu, H. Y., Wang, Q., Zhao, C. H. (2012): Early millet use in northern China. - Proceedings of the National Academy of Sciences America 109: 3726-3730.

[50] Yang, Y. J., Zhang, J. H., Chen, L. J., Ji, A. Q., Zhao, H. M., Guo, P. Y. (2018): Effects of fertilizer levels and plant density on chlorophyll content, chlorophyll fluorescence and grain yield of Setaria italica. - International Journal of Agriculture Biology 20: 737-744.

[51] Zörb, C., Ludewig, U., Hawkesford, M. J. (2018): Perspective on wheat yield and quality with reduced nitrogen supply. - Trends Plant Science 23(11): 1029-1037. 


\section{APPENDIX}

Figure A1. A diagram of the used experimental design (a quadratic general rotation combination design with a 5-factor-5-level was used, with 32 treatments and three replications). 96 units were run in a fully randomized block design, with protection rows placed around the experimental location)

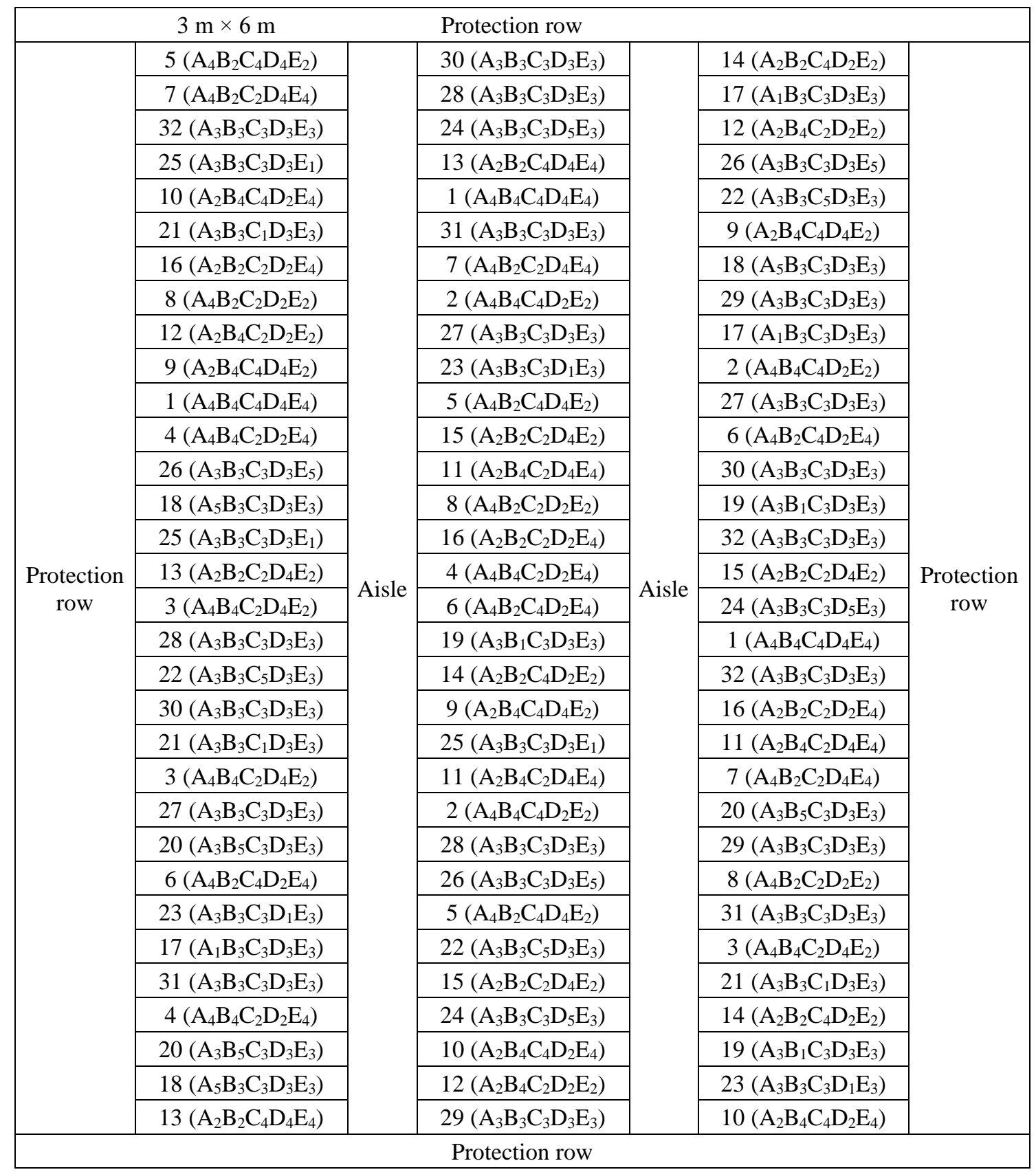

The numbers in the table are treatment codes, which are the same as the treatment codes in Table 2 of the main text. $A_{1}, A_{2}, A_{3}, A_{4}$, and $A_{5}$ correspond to nitrogen fertilizer levels of $0,69,138,207$, and 276 $\mathrm{kg} \mathrm{ha}^{-1}$ correspondingly; $\mathrm{B}_{1}, \mathrm{~B}_{2}, \mathrm{~B}_{3}, \mathrm{~B}_{4}$, and $\mathrm{B}_{5}$ equate to $0,36,72,108$, and $144 \mathrm{~kg} \mathrm{ha}^{-1}$ of phosphate fertilizer, respectively; $\mathrm{C}_{1}, \mathrm{C}_{2}, \mathrm{C}_{3}, \mathrm{C}_{4}$, and $\mathrm{C}_{5}$ equate to $0,37.5,75,112.5$, and $150 \mathrm{~kg} \mathrm{ha}^{-1}$ of potash fertilizer, respectively; $D_{1}, D_{2}, D_{3}, D_{4}$, and $D_{5}$ equate to $0,60,120,180$, and $240 \mathrm{~kg}$ ha- -1 of selenium fertilizer, respectively ; $\mathrm{E}_{1}, \mathrm{E}_{2}, \mathrm{E}_{3}, \mathrm{E}_{4}$, and $\mathrm{E}_{5}$ correspond to $0,20,40,60$, and $80 \mathrm{~g}$ ai ha $\mathrm{h}^{-1}$ of the various herbicide levels 
Figure A2. The photos of the experimental culture or equipment
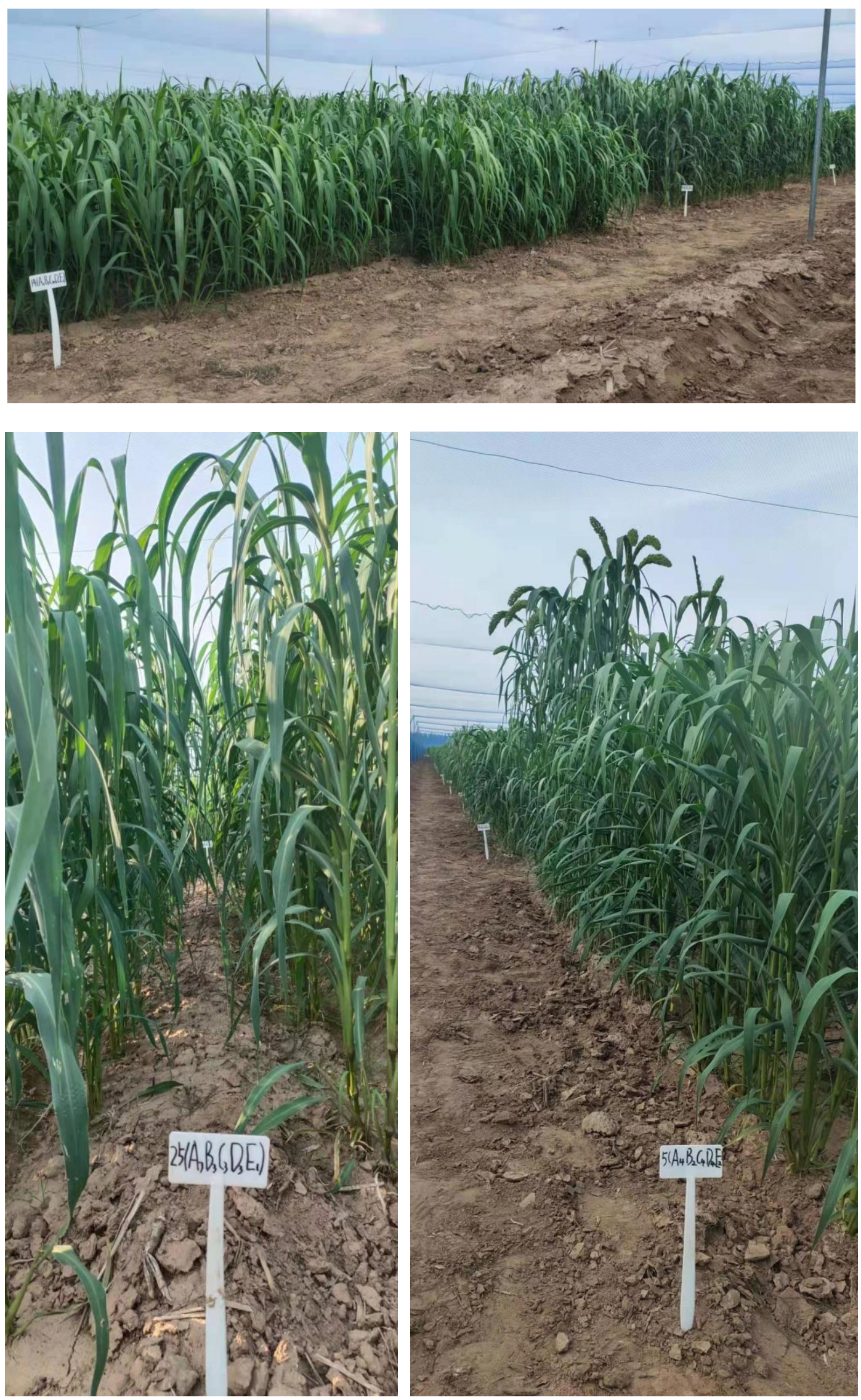

APPLIED ECOLOGY AND ENVIRONMENTAL RESEARCH 19(6):4231-4249.

http://www.aloki.hu • ISSN 15891623 (Print) • ISSN 17850037 (Online)

DOI: http://dx.doi.org/10.15666/aeer/1906_42314249

(c) 2021, ALÖKI Kft., Budapest, Hungary 

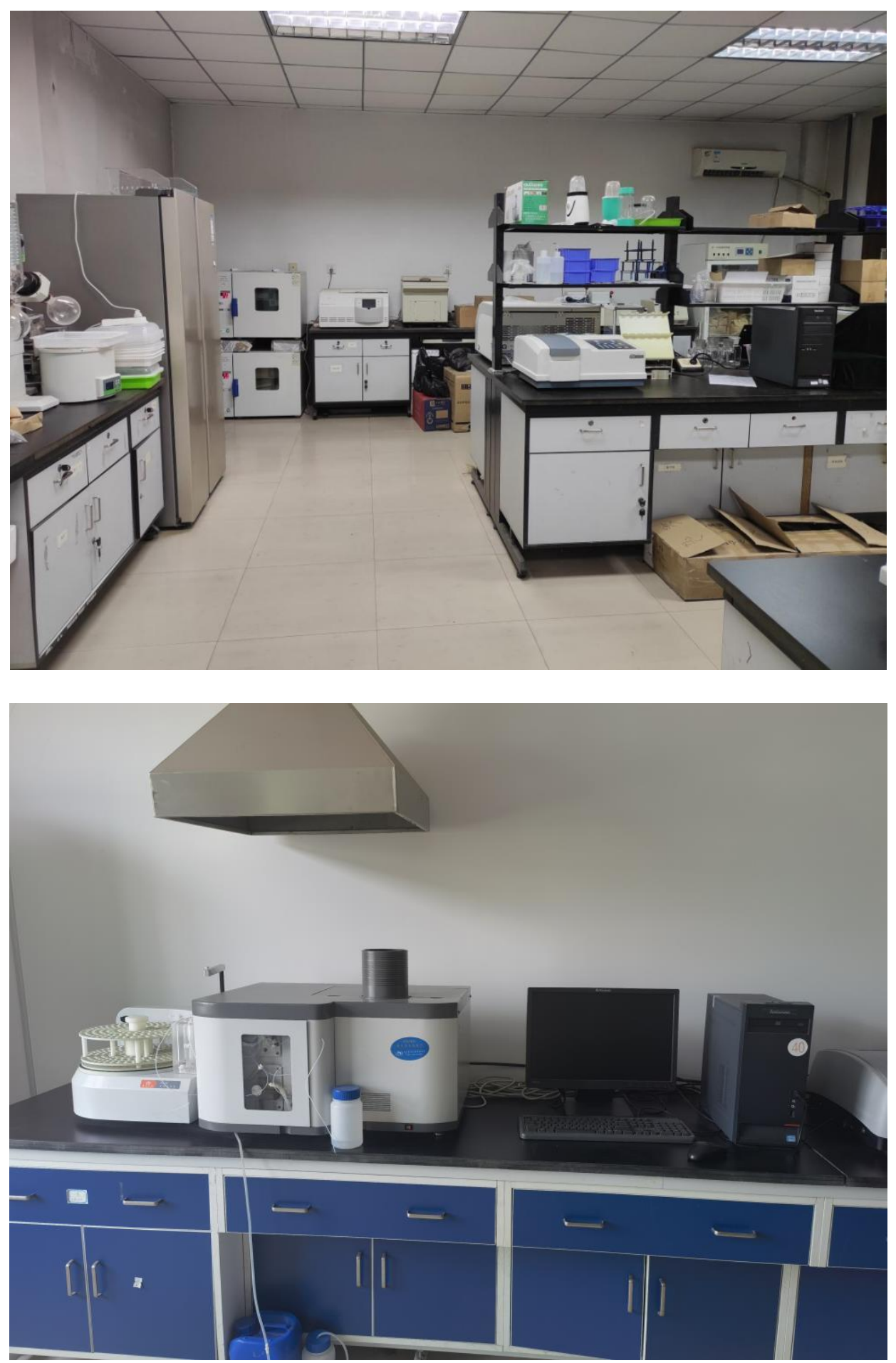